Jurnal Teknologi, 37(A) Dis. 2002: 37-46

(C) Universiti Teknologi Malaysia

\title{
DATA TRANSFER BETWEEN CAD SYSTEM AND RP SYSTEM: A REPORT
}

\author{
SYAIMAK ABU SYUKUR ${ }^{1} \&$ MASINE MD TAP ${ }^{2}$
}

\begin{abstract}
Rapid Prototyping $(\mathrm{RP})$ is a technology that transform a design generated in Computer Aided Design (CAD) to a 3D model parts. CAD models are usually done on a CAD system and then transported into the RP system. A good interface between the CAD and the RP system is one of the key factors of producing a good quality prototype. This paper reports on the results of an experimentation carried out to identify the problems in transferring data between a CAD system (UNIGRAPHICS) and an RP system (QUICKSLICE). Based on the experimentation's results and analysis, a basic guideline is proposed for a safer data transfer between the CAD system (UNIGRAPHICS) and an RP system (QUICKSLICE).
\end{abstract}

Key words: $\quad$ CAD, CAM, CAD/CAM, Rapid Prototyping

\begin{abstract}
Abstrak. Sistem Rapid Prototyping (RP) ialah teknologi yang menukar sesuatu reka bentuk yang di bina dalam Computer Aided Design (CAD) ke suatu komponen model 3D. Model CAD biasanya dibina dalam sistem CAD yang kemudiannya dihantar ke sistem RP. Antaramuka yang baik antara system CAD dan system RP adalah salah satu faktor penting dalam menghasilkan prototaip yang berkualiti tinggi. Kertas kerja ini melaporkan hasil uji kaji yang dijalankan untuk mengenal pasti masalah-masalah dalam memindahkan data antara satu sistem CAD (UNIGRAPHICS) dan satu sistem RP (QUICKSLICE). Berdasarkan hasil uji kaji dan analisis yang dijalankan, satu garis panduan dicadangkan untuk perpindahan data yang lebih berkesan antara sistem CAD (UNIGRAPHICS) dan sistem RP (QUICKSLICE).
\end{abstract}

Kata kunci: $\quad \mathrm{CAD}, \mathrm{CAM}, \mathrm{CAD} / \mathrm{CAM}$, Rapid Prototyping

\subsection{INTRODUCTION}

$\mathrm{CAD}$ is the creation and optimisation of the engineering design using the computer as a productivity tool [1]. Computer Aided Manufacturing (CAM) refers to the use of computer to control the activities on the manufacturing floor [2]. The integration between $\mathrm{CAD}$ and CAM is essential in order to improve the productivity in a manufacturing environment and also to ensure the quality of the product produced with shorter time and less cost. Rapid Prototyping (RP) system is one example of a technology that benefited from the integration of CAD and CAM. McMahon and Browne [3] defined $\mathrm{RP}$ as a term used to describe a number of techniques which rapidly produce solid

\footnotetext{
${ }^{1}$ Universiti Kebangsaan Malaysia, Bangi, Selangor.

${ }^{2}$ Universiti Teknologi Malaysia, Skudai, Johor.
} 
physical models of components and products using 3D computer data by a group of relatively new manufacturing technologies.

Basically, RP imports data or model from a CAD system and uses it to build the physical prototype of the model. This prototype of the model is useful in realising the conceptualisation of a design [4]. RP can produce a real 3D physical model that can be physically checked or evaluated [5]. The model can also be used to produce moulds and dies quickly thus, reducing time and cost of introducing new products.

However, to some extent the quality of the prototype produced is dependent on the quality of the interface between the CAD and the RP system. Any data lost or distorted during the interface between the systems will effect the quality of the prototype produced. This paper reports on the results of the tests conducted to identify the problems in the interface between a CAD system (UNIGRAPHICS) and an RP system (QUICKSLICE). Recommendations are then made to overcome these problems.

\subsection{INTERFACE BETWEEN A CAD SYSTEM AND AN RP SYSTEM}

The main function of the interface is to handle and transfer the data of a given part from CAD systems to RP systems [6,7]. An RP system uses the data from a CAD system to produce a model or prototype of a part, component or product. However, an RP system cannot use directly the data from a CAD system. The data need to be converted to a suitable file format that can be read and understood by the RP system [8]. Some of the file format that can be used in RP system are; HPGL (Hewlett-Packard Graphics Language), STL (Stereolithography Tessellation Language), IGES (International Graphics Exchange Standard), STEP (Standard of The Exchange of Product), and CLI (Common Layer Interface) [9].

There are three basic steps in producing a prototype on an RP system:

1. A part is modelled on a CAD/CAM system and must be represented as closed surface to enable the system to create solid object.

2. The solid or surface model is then converted into a file format that the RP system can understand.

3. The RP system then analyses the file to generate the commands to fabricate the model on the RP machine.

Two factors that can affect data integrity and the quality of the model produced during the interface between $\mathrm{CAD}$ and $\mathrm{RP}$ are: the format used to translate the $\mathrm{CAD}$ model into a file that RP understands and the tessellation process that the file format generated and used.

Many researches have tried to identify the accuracy factors that affect the quality of the prototypes produced due to the data transfer between a CAD system and an RP system. Some of them have focused on the general defects that occurred during the 
data transfer [9,10]; while some have focused on the defects that occur due to the file format used (STL) in interfacing between the CAD and the RP systems [10-15].

Fadel and Kirchman [9] identified seven problems as the general defects on data transfer between a CAD system and an RP system. They are tessellation process (a process that generates triangles to approximate CAD model), convex boundary error, CAD to STL translation, vectorization, laser beam or jet thickness, $z$ effect (adaptive slicing) and orientation of the model in the RP machine. Cheng et al. [10] listed two general defects which are tessellation and missing features due to constant slicing thickness.

Jurrens [11] identified errors that stemmed from the STL file as gaps, inverted facet normal, incorrect facet intersections and denegerate facets. Koelsch [12] identified the limitations in STL file, as misoriented, missing and overlapping especially when a complex geometry is converted into the STL files. While Ngoi et al. [13] found undesirable gaps occurring on the surface of the models. Noaker and Paula [14], discovered defects on STL files such as missing facets, overlapping or misalign edges, inaccurate and inconsistent surface normal. In a specific study done by Leong et al. [7] on errors of STL files, they discovered problems such as; missing facets, gaps, degenerated facets, overlapping facets and non-manifold conditions.

There are numerous errors that affect the RP process and a better understanding of these errors can lead to a minimisation of their effect.

\subsection{RESEARCH METHODOLGY}

This study aimed to assess data integrity specifically between CAD system (UNIGRAPHICS) and RP system (QUICKSLICE) and attempt to identify problems on the STL Binary file that is used in transferring data between these two system. STL file is a syntax describing the boundary of a model in a polyhedral (usually triangular) formats [6].

STL file is generated from a precise CAD model using tessellation process. STL file consists of an unordered list of triangular facets representing the outside surface of the object. This triangular facets are described by a set of $X, Y$ and $Z$ co-ordinates for each of the three vertices and a unit normal vector with $X, Y$ and $Z$ to indicate which side of facet is inside the object. There are two formats of STL file, the ASCII or text file and the Binary file. Both files describe the 3D facets and their normal.

Figure 1 shows the procedure for the experimentation. In the first step, a CAD model was created and built using UNIGRAPHICS (version 11.1.1). Then, the model that was saved in .prt file is then translated to STL file using the default value of adjacency and triangle tolerances determined by UNIGRAPHICS for tessellation process. The format of the STL file used in the experiment is the Binary type.

The third step is identify and check for errors. Here, the STL file will be viewed and verified using ADMESH (version 0.94), Solid View (version 3.31) and STL View (version 6.0). These three tools are among the tools available to facilitate the bridging 


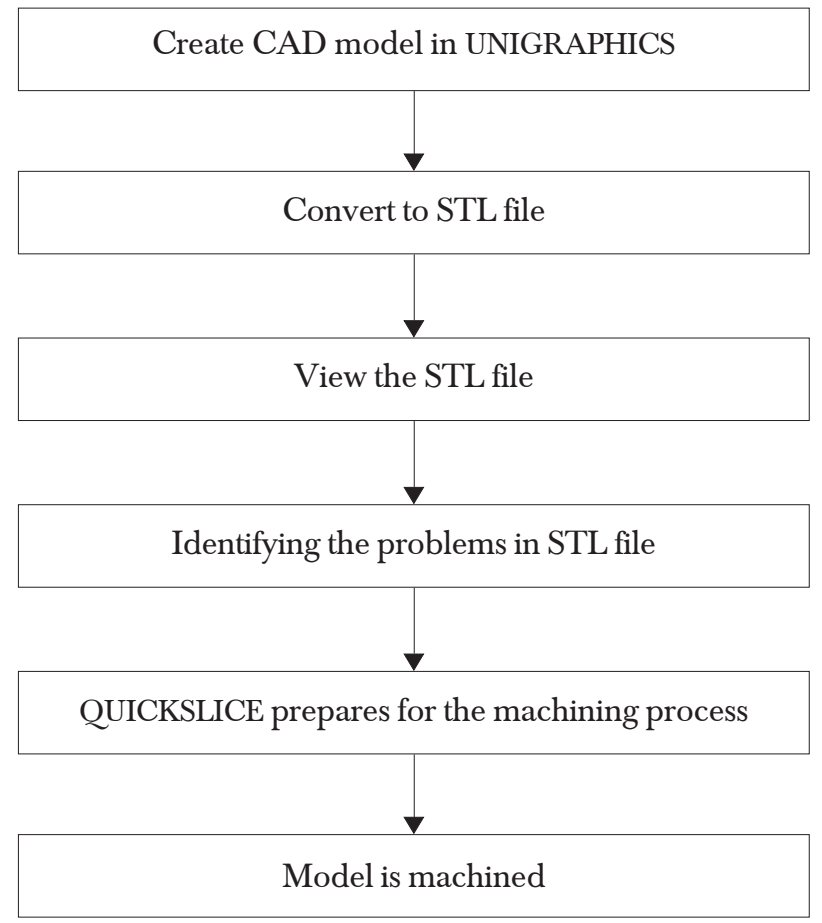

Figure 1 Procedures for the experimentation

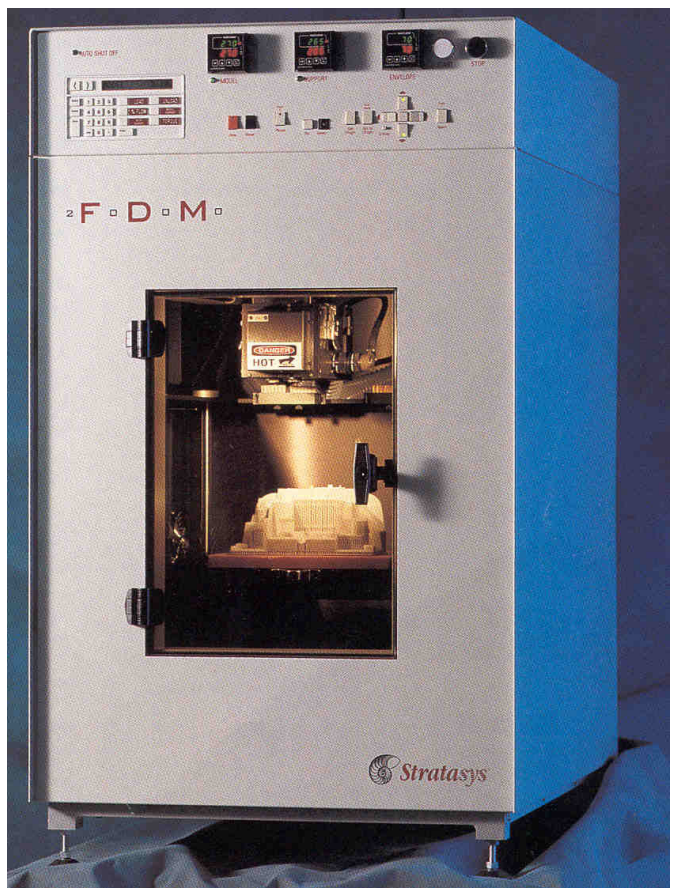

Figure 2 FDM 2000 Machine 


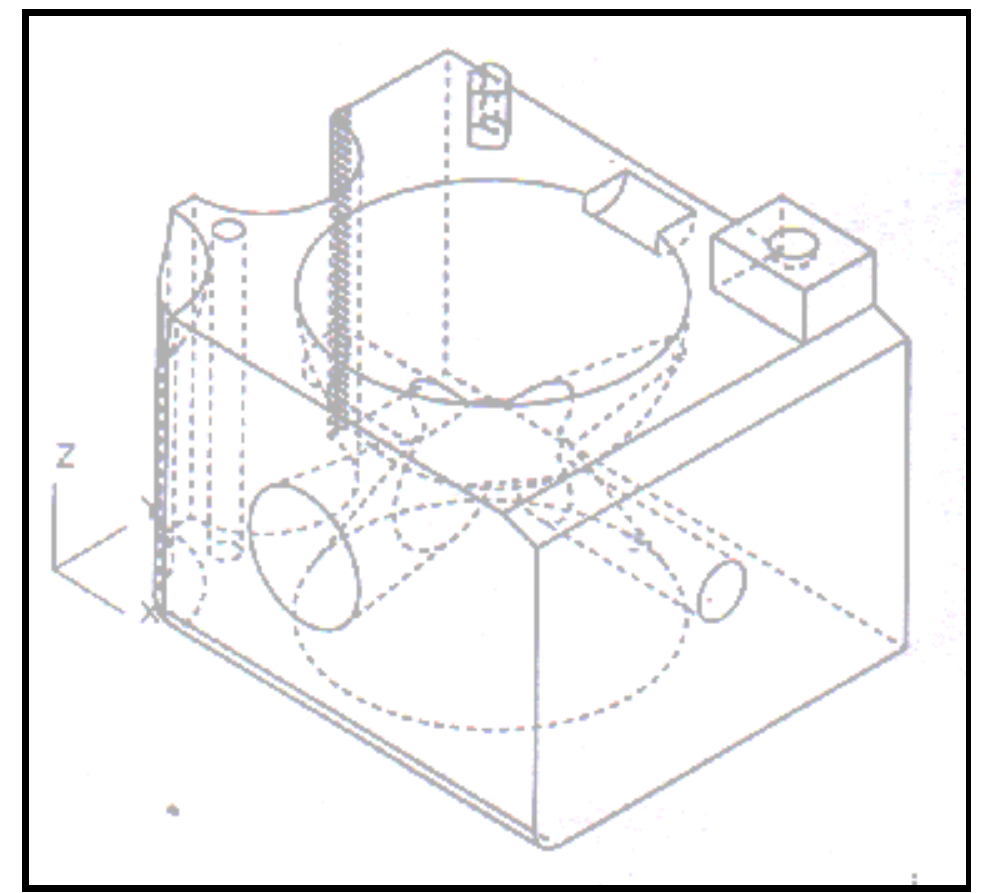

Figure 3 Model created for the experiment

between CAD and RP. It allows a user to verify and check various errors that might occurr in the STL file.

Then, the STL file is transferred to QUICKSLICE for slicing and machining process preparation. Finally the model will be machined using the FDM (Fused Deposition Machine) 2000 Machine (refer Figure 2). Figure 3 shows the model created for this experiment. The model that is designed consists almost all elements contained in Solid, Features and Freeform Modeling. The elements that are considered in the model are primitives, operations, form features, Boolean operations and swept feature. It is designed to consist as many as possible elements that UNIGRAPHICS has so that the effects of the data transfer on each element can be observed.

\subsection{RESULTS}

Table 1 shows the type of errors that occurred and the number of errors for each type that was detected. In these experiments, the errors detected are gaps, unshared edges, degenerates triangles, false normal and the number of shells.

\section{(i) Gaps}

These occurred due to missing triangles on the model. 
Table 1 List of the errors detected

\begin{tabular}{|l|l|}
\hline Gaps & 2 \\
\hline Unshared edges & 4 \\
\hline Degenerated triangles & 4 \\
\hline Facets with 1 disconnected edges & 16 \\
\hline Facets with 2 disconnected edges & 0 \\
\hline Facets with 3 disconnected edges & 0 \\
\hline False normal & 64 \\
\hline Number of shells & 5 \\
\hline
\end{tabular}

\section{(ii) Unshared edges}

Unshared edge is the error that occurred when an edge of a triangle on the solid object is unshared. This is because in a triangular mesh, that represents a solid object, each triangle edge must be shared by one other triangle edge.

\section{(iii) Degenerates triangle}

This geometrical degeneracy of a facet occurs when all the facets' edges are collinear even though all of its vertices are distinct. A degenerate facet is a facet that has two or more identical vertices. The resulting facet is just a line (if two vertices are the same) or could even be a point (if all three vertices are the same).

\section{(iv) False normal}

False normal occurred when the points that form a triangle are not listed in the correct order. Normal defines the orientation of a plane and it is perpendicular to the plane.

\section{(v) Number of shells}

For a normal close solid, it consists of a single shell, while a hollow object such as a hollow sphere will have two shells or connected surface regions. More than one or two shells as described above will indicate error in the number of shell and the object is composed of a multiple solids or disconnected surface regions, which may not be built correctly. 
All these errors could lead to the production of inaccurate and defective prototype. Thus, it is important to eliminate or minimise these errors in order to produce a good quality prototype.

\subsection{GUIDELINE IN DATA TRANSFER BETWEEN CAD (UNIGRAPHICS) AND RP (QUICKSLICE)}

The results of the experiments conducted were analysed and the guidelines are proposed in this section. The objective of the guidelines is to eliminate or minimise the errors that may occur in transferring data between UNIGRAPHICS and QUICKSLICE. However, this paper only addresses the problems occurring during the data transfer between the two systems and does not address the problems related to machine factors such as the machine's slice interval, tip size, road width and the orientation that may effect the quality of a prototype. The guidelines are divided into three different aspects or areas:

\subsection{Before Conversion to STL File}

Steps to be followed before converting a CAD model to an STL file:

(i) The CAD model has to be on the positive area of the $x, y$ and $z$ co-ordinates. Minimum values of $x, y$ and $z$ co-ordinates should be above zero.

(ii) The CAD model created should be in a closed solid model. There should be no other elements such as 2D elements in the model.

\subsection{Conversion Process of STL Files}

In the conversion windows, UNIGRAPHICS will prompt the user to choose the value of the tolerance. There are two types of tolerances involved; the adjacency tolerance and the triangle tolerance. The values of tolerances are dependent on the shape and the size of the model. It also depends on the experience and the knowledge of the user. A closer tolerance is recommended as it will accurately approximate the model as compared to a wider tolerance value but a closer tolerance will require more triangles and larger file size.

\subsection{Transferring STL File to QUICKSLICE}

Once the CAD model is converted to an STL file, it is then sent to RP system (QUICKSLICE). Before this file is transferred, the following need to be done;

(i) The STL file has to be checked or verified for any errors or defects. 
(ii) For any errors that occurred, the STL file should be repaired and then verified again to ensure that the file is free from any error.

There are two methods to verify and repair the STL file. The first method is by using the tools (software) available, while the second method is to verify and check the STL file manually.

In the first method, the tools provided will automatically repair the flaws in the STL file by choosing the right command provided. It is able to read or check the STL file either in the Binary format or in the ASCII format. It it easier and faster as compared to doing it manually. Some of the tools available are ADMESH, STL View, Solid View, Magics, CIDES and Rapid Tool.

In the second method, it requires a user to check the file line by line for errors. The errors detected can then be repaired line by line and this requires an experienced person in order to check and repair the STL file. It is a tedious and time consuming task and may be subjected to human errors.

\subsection{CONCLUSION}

$\mathrm{RP}$ is relatively a new technology and this technology is developing and improving in various ways. It is becoming one of the most important technologies in producing a product. It helps to reduce the product development cycle and give its user a competitive edge in the ability to respond quickly to changes in the market. In order to produce good quality models or prototypes, the errors or problems occurred in the interfacing between a CAD system and an RP system must be identified and avoided.

This paper managed to identify six different types of errors that occurred when transferring data between a CAD system (UNIGRAPHICS) and an RP system (QUCIKSLICE). Guidelines were drawn out on how to avoid such errors and provide a safe data transfer between CAD system (UNIGRAPHICS) and RP system (QUICKSLICE). The guidelines were divided into three aspects, that is, before the conversion to STL file, during the conversion to STL file and before sending the STL file to RP system (QUICKSLICE). By following the guidelines, the errors that may arise from the interface could be eliminated or at least minimised.

However different CAD systems and RP systems may produce different sets of error due to the variation in how each system handle and structure data. Although the guidelines provided here is specifically for UNIGRAPHICS and QUICKSLICE, it may also be used for similar systems.

\subsection{FUTURE RESEARCH}

Further research is recommended to improve data transfer between CADCAM systems. They are; 
(i) Research can be conducted in order to evaluate the data transfer between a $\mathrm{CAD}$ and RP system using more than one 3D solid model instead of using one model as in this study. Different effects on the models could be verified.

(ii) Assessment should be made on the effectiveness of the softwares used to identify, repair and verify the errors occurring in the data transfer. Besides the softwares used in this project, other available softwares are, such as; Rapid Prototyping Module (RPM) from Imageware, Rapid editor from DeskArtes, Pogo 3.0 from POGO International Inc., Clemson's Intelligent Design Environment for Stereolithography (CIDES), SHAPES, from XOX Corporation and Magics from Materialise. These softwares claimed to bridge the gap between $\mathrm{CAD}$ and RP systems.

(iii) A research also can be done on assessing the $\mathrm{CAD}$ to $\mathrm{RP}$ translation using other type of CAD system such as Auto CAD, Pro Engineers and others.

(iv) Studies should also be conducted on the effect of data transfer on machine related problems such as machine's slice interval, tip size, road width and orientation.

\section{ACKNOWLEDGEMENT}

The authors would like to thank for the cooperation provided by the Manufacturing Laboratory, Department of Production and Industrial Engineering, Universiti Teknologi Malaysia and Universiti Kebangsaan Malaysia in conducting this project.

\section{REFERENCE}

[1] Bedworth, D. D., M. R. Henderson, and P. M. Wolfe. 1991.Computer-Integrated Design and Manufacturing. USA: McGraw-Hill Inc.

[2] Rembold, U., B. O. Nnaji, and A. Storr. 1993. Computer Integrated Manufacturing \& Engineering. USA: Addison-Wesley.

[3] McMahon, C., and J. Browne. 1998. Principles, Practice and Manufacturing Management (2 ${ }^{\text {nd }}$ Edition). England: Addison-Wesley.

[4] Chua, C. K., and K. F. Leong. 1997. Rapid Prototyping: Principles and Applications in Manufacturing. Singapore: John Wiley and Sons Inc.

[5] Ribiero, F. 1998. 3D Printing with Metals. Computing and Control Engineering Journal. 9(1): 31-38.

[6] Leong, K. F., C. K. Chua, and Y. M. Ng. 1996. A Study of Stereolithography File Error and Repair: Part I: Generic Solution. International Journal of Advanced Manufacturing Technology. 12: 407-414.

[7] Leong, K. F., C. K. Chua, and Y. M. Ng. 1996. A Study of Stereolithography File Error and Repair: Part II: Special Case. International Journal of Advanced Manufacturing Technology. 12: 415-422.

[8] Koc, B., M. Yawei, and S. L. Yuan. 2000. Smoothing STL Files by Max-fit Biarc Curves for Rapid Prototyping. Rapid Prototyping Journal. 6(3): 186-205.

[9] Fadel, G.M., and C. Kirschman. 1996. Accuracy Issues on CAD to Rapid Prototyping Translation. Rapid Prototyping Journal. 2(2): 4-17.

[10] Cheng, W., J. Y. H. Fuh, A. Y. C. Nee, Y. S. Wong, H. T. Lo, and T. Miyazawa. 1995. Multi-objective Optimization of Part-building Orientation in Stereolithography. Rapid Prototyping Journal. 1(4): 12-23. 
[11] Jurrens, K. K. 1999. Standards for the Rapid Prototyping Industry. Rapid Prototyping Journal. 5(4):69-178.

[12] Koelsch, J. R. 2000. Should STL be the Standard. Automotive Plastics. 58(4): 30-36.

[13] Ngoi, B. K. A., C. K. Chua, S. Ngai, and F. T. L Tay. 1993. Development of a Stereolithography Preprocessor for Model Verification. Computing and Control Engineering Journal. 4(4): 218-224.

[14] Noaker, M. P. 1996. CAM's Solid Modeling Connection. Manufacturing Engineering. 117: 70.

[15] Chua, C. K., G. K. Gan, and M. Tong. 1997. Interface between CAD and Rapid Prototyping System. Part I: A Study of Existing Interfaces. International Journal of Advanced Manufacturing Technology. 13: 566-570. 